\title{
A subset of hypertrophic cardiomyopathy patients is predisposed to angulated septum
}

\author{
Rebecca Liu", Gladys Rodriguez ${ }^{1}$, Steffen Huber ${ }^{2}$, Sameh Hozayen$^{1}$, William J McKenna ${ }^{3}$, Daniel Jacoby ${ }^{1}$ \\ From 18th Annual SCMR Scientific Sessions \\ Nice, France. 4-7 February 2015
}

\section{Background}

Hypertrophic cardiomyopathy (HCM) is a complex genetic disease with marked morphofunctional heterogeneity. Some HCM patients develop obstructive symptoms later in life, long after cessation of hypertrophic progression. The mechanism underlying this phenomenon is poorly understood. It is known that aorto-septal angulation progresses with age. However, the relationship between age, septal angulation, and HCM subtype has not been explored. In this present study, we examined the relationship between age, aorto-septal angulation and subtypes of HCM.

\section{Methods}

Control normal subjects $(\mathrm{n}=19)$ and consecutive HCM patients with apical, concentric, and septal subtypes $(\mathrm{n}=53)$ were identified from the MRI database at YaleNew Haven Hospital. Angulated septal angle, the angle between the right septal surface and anterior aortic wall during end systole and diastole, was measured blindly by two readers. Disagreements between two reads $>10^{\circ}$ were excluded. In addition, we further age stratified our cohort of septal subtype (above or below 40 years) to explore differences in the pattern of aorto-septal angle over age.

\section{Results}

Patients with septal, but not apical or concentric subtypes, exhibit more acute angulated septum versus controls in end-systole $(\mathrm{p}=0.008,0.326$, and 0.167 , respectively). The acuity of this angle increased with age in controls $(\mathrm{p}=0.0009)$. Interestingly, HCM patients with septal hypertrophy deviated from this pattern, demonstrating early angulation without progression over age $(\mathrm{p}=0.918)$. The associations above remained significant in end-diastole.
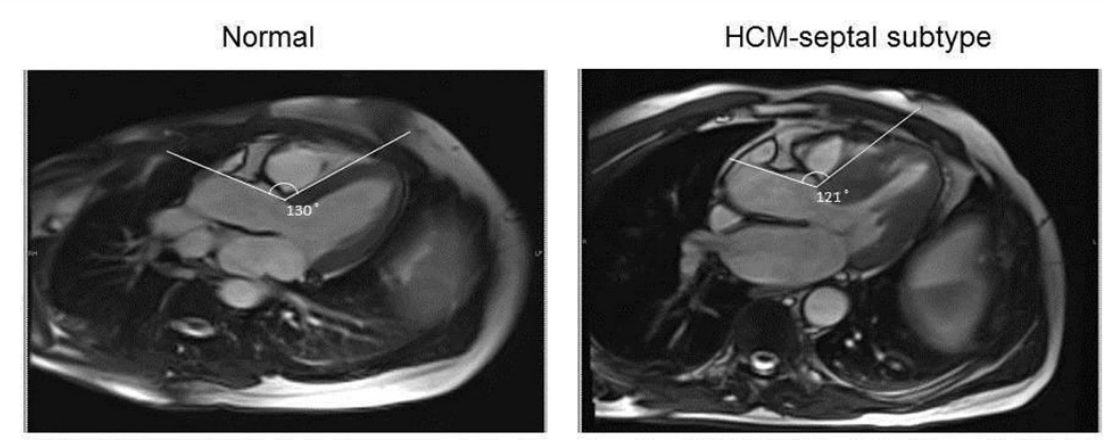

Figure 1 Patients with septal variant of hypertrophic cardiomyopathy exhibit more acute angulated septum than normal controls. The angulated septal angle, measured as the angle between the right septal surface and anterior aortic wall, is shown in the MRI of a normal control (left) and a patient with septal variant of HCM (right).

IInternal Medicine, Yale University School of Medicine, New Haven, CT, USA Full list of author information is available at the end of the article 


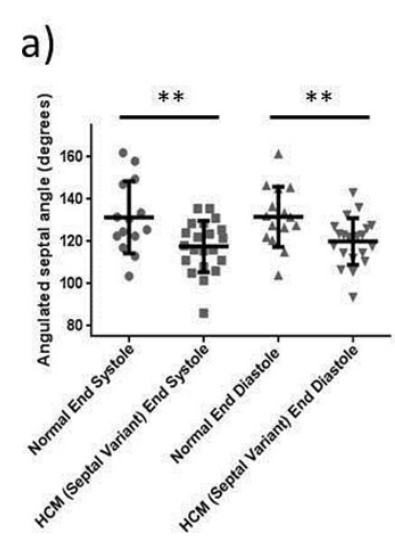

b)
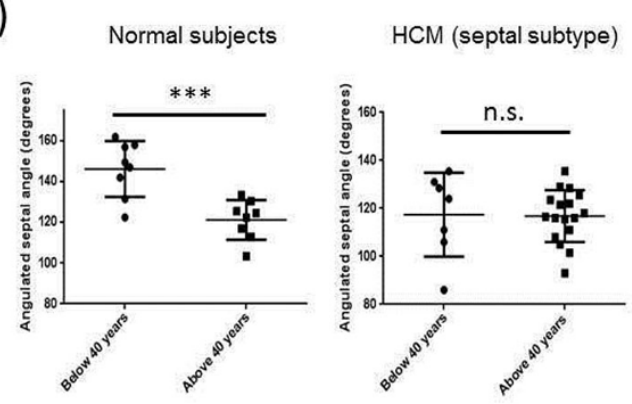

Figure 2 A subset of hypertrophic cardiomyopathy patients is predisposed to angulated septum. a) Patients with septal variant of HCM exhibit more acute angulated septum compared to normal controls in both end-systole and end-diastole. b) While normal subjects demonstrate progression of angulated septum over age, HCM patients with septal hypertrophy deviate from this pattern, with no progression. ${ }^{* *} p<0.001,{ }^{* *}$ $p<0.01$, n.s. $=$ non-significant.

\section{Conclusions}

This novel finding suggests that HCM patients with septal, but not apical or concentric patterns of hypertrophy are predisposed to angulated septum regardless of age. Future studies are needed to assess correlations of symptom severity or obstruction with angle acuity. This will offer insight to the possible etiopathological link between angulated septum and morphofunctional subtype of HCM.

\section{Authors' details}

${ }^{1}$ Internal Medicine, Yale University School of Medicine, New Haven, CT, USA.

${ }^{2}$ Diagnostic Radiology, Yale University School of Medicine, New Haven, CT,

USA. ${ }^{3}$ University College London, London, UK.

Published: 3 February 2015

doi:10.1186/1532-429X-17-S1-P272

Cite this article as: Liu et al:: A subset of hypertrophic cardiomyopathy patients is predisposed to angulated septum. Journal of Cardiovascular Magnetic Resonance 2015 17(Suppl 1):P272.

Submit your next manuscript to BioMed Central and take full advantage of:

- Convenient online submission

- Thorough peer review

- No space constraints or color figure charges

- Immediate publication on acceptance

- Inclusion in PubMed, CAS, Scopus and Google Scholar

- Research which is freely available for redistribution

Submit your manuscript at www.biomedcentral.com/submit 